\title{
Sustentabilidade em sistema de produção orgânica e convencional de agricultores familiares da Transamazônica, Pará
}

\section{Sustainability in organic and conventional production system for family farmers in Transamazônica, Pará}

\author{
Kamila de Castro Oliveira Rocha ${ }^{1}$; Carla Giovana Souza Rocha ${ }^{1 *}$; Tayse \\ Rocha de Carvalho Soares ${ }^{1}$
}

\begin{abstract}
RESUMO
Diante das transformações ocorridas no meio natural ao longo das últimas décadas na região da Transamazônica, localizada na região Sudoeste do estado do Pará, a pesquisa teve por objetivo analisar a sustentabilidade em sistema de produção orgânica e convencional de agricultores familiares da região. Foram realizadas entrevistas a dez agricultores familiares. Destes, cinco promovem a produção de forma orgânica e cinco, a produção convencional. Os agricultores orgânicos entrevistados foram os cooperados da COPOPS do município de Uruará e, em Brasil Novo os da COPOXIN. Os dados foram representados graficamente pela ferramenta MESMIS por meio de atributos estabelecidos nas dimensões ambiental, social e econômica. Os agroecossistemas orgânicos apresentaram melhores índices em termos econômico, social e ambiental, mas precisam ser fortalecidos nos aspectos das práticas orgânicas e da organização social, para que garantam melhor performance na renda e no manejo dos sistemas. O desempenho dos sistemas convencionais foi considerado como crítico, principalmente na questão ambiental.
\end{abstract}

Palavras-chave: Produção Orgânica; Agricultura Familiar; MESMIS.

\begin{abstract}
In view of the changes that have taken place in the natural environment over the last few decades in the Transamazônica region, located in the Southwest region of the state of Pará, the research aimed to analyze the sustainability in the organic and conventional production system of family farmers in the region. Interviews were conducted with ten family farmers. Of these, five promote organic production and five, conventional production. The organic farmers interviewed were COPOPS members from the municipality of Uruará and Brasil Novo, those from COPOXIN. The data were graphically represented by the MESMIS tool through attributes established in the environmental, social and economic dimensions. Organic agroecosystems showed better rates in economic, social and environmental terms, but they need to be strengthened in the aspects of organic practices and social organization, so that they guarantee better performance in terms of income and in the management of the systems. The performance of conventional systems was considered critical, especially in terms of the environment.
\end{abstract}

Keywords: Organic Production; Family farming; MESMIS.

${ }^{1}$ Universidade Federal do Pará

*E-mail: crocha@ufpa.br 


\section{INTRODUÇÃO}

Ao longo das últimas cinco décadas, a região da Transamazônica no Sudoeste do estado do Pará sofreu grandes transformações em seu meio natural. No início dos anos de 1970, um modelo desenvolvimentista foi instalado a partir do Projeto Integrado de Colonização (PIC Altamira) com o propósito de colonizar o território, ampliando expressivamente a ocupação das terras públicas para atividades agropecuárias, e ocasionando expulsão de povos indígenas e de populações tradicionais. Em decorrência, os problemas ambientais se intensificam com a aceleração da extração ilegal de madeira e minério e com a expansão da criação extensiva de gado bovino. A falta de políticas de ordenamento fundiário, ambiental, de apoio à consolidação das unidades de conservação e de terras indígenas, e de fomento à agricultura sustentável alimentam índices crescentes de desmatamento, com destaque para o aumento do índice ocorrido na Amazônia, notadamente em florestas públicas no estado do Pará (IMAZON, 2021).

Verifica-se também que a produção de alimentos para a autossustento das famílias camponesas e para o mercado local e regional tem sofrido perda ao longo dos anos, e sistemas menos diversificados ou mesmo especializados em commodities já são dominantes (SILVA, 2018; ROCHA, 2016).

Em outra perspectiva socioambiental, e na contraposição a esse modelo preconizado pela modernização agrícola conservadora (MARTINS, 1994), o debate sobre sustentabilidade e agroecologia foi ampliado no Brasil. Como exposto por Altieri e Nicholls (2000, p. 24), sustentabilidade "é a medida da capacidade de um agroecossistema para manter a produção ao longo do tempo, na presença de repetidos constrangimentos ecológicos e pressões socioeconômicas". Essa ideia de sustentabilidade é complexa, mas tem sido a preocupação de parte da sociedade nos últimos anos, abrange diversas abordagens nas dimensões ambiental, político, econômico e social. Assim como o termo desenvolvimento sustentável, que foi muito difundido e gera ainda muitas controvérsias. Entretanto, ainda é útil por mostrar o desafio político de definir ações efetivas e obrigações humanas, com o objetivo de atender as necessidades atuais sem comprometer as gerações futuras.

$\mathrm{Na}$ perspectiva de construir sistemas agroalimentares ou agroecossistemas sustentáveis, a agricultura orgânica e a agroecologia têm se expandido em termos de pesquisas, políticas públicas, mercados, processos produtivos e organizacionais de diversos setores sociais, no intuito de assegurarem que as alternativas sustentáveis sejam 
viabilizadas. Petersen (2013) defende que o fortalecimento da agroecologia também passa pela análise e proposições de marcos institucionais adequados para que os seus princípios sejam incorporados como referência das ações públicas.

Assim, a agroecologia se destaca como um dos caminhos para se obter a sustentabilidade dos sistemas agroalimentares, de preservar a biodiversidade, pois suas bases fazem com que os processos ecológicos sejam considerados, promovendo o ciclo de conservação da natureza. O olhar nos processos ecológicos é um dos focos privilegiado na Agroecologia, que pode ser definida como uma Ciência que se utiliza da abordagem sistêmica e interdisciplinar, conforme mencionado por Altieri e Nicholls (2000).

La disciplina científica que enfoca el estudio de la agricultura desde uma perspectiva ecológica se denomina «agroecología» y se define como un marco teórico cuyo fin es analizar los procesos agrícolas de manera más amplia. El enfoque agroecológico considera a los ecosistemas agrícolas como las unidades fundamentales de estudio; y en estos sistemas, los ciclos minerales, las transformaciones de la energía, los procesos biológicos y las relaciones socioeconómicas son investigados y analizados como un todo (ALTIERI; NICHOLLS, 2000, p. 14).

Em relação à agricultura orgânica, Bellon et al. (2011) a define como o: "sistema geral de gestão agrícola e de produção de alimentos que combina as melhores práticas ambientais e um elevado nível de biodiversidade", e reforçam o que a agricultura orgânica e a agroecologia têm objetivos em comum como enfrentar o desafio de segurança alimentar e preservação do meio ambiente.

A produção de forma orgânica incorpora um dos princípios dos sistemas agroecológicos que é da adoção de métodos culturais, biológicos e mecânicos que não usem materiais sintéticos ou organismos geneticamente modificados (BRASIL, 2003). E na região da Transamazônica, esse tipo de produção representa um modelo a ser adotado como alternativa para diminuir a quantidade de área desmatada, combater os problemas de contaminação e degradação ambiental e para a melhoria da qualidade dos produtos e da vida. Neste sentido, pensar em um modelo de produção orgânica contribui para que os estabelecimentos agrícolas formem em médio e longo prazo uma estabilidade ecológica em seus sistemas.

Diante do exposto o objetivo desse artigo é analisar a sustentabilidade em agroecossistemas de produção orgânica e convencional de agricultores familiares da região Transamazônica com o auxílio da ferramenta MESMIS, buscando identificar os desafios para o fortalecimento dos sistemas orgânicos. 
A pesquisa de campo foi desenvolvida por meio de entrevistas diretamente nas propriedades rurais localizadas nos municípios de Brasil Novo e Uruará. O município de Brasil Novo localiza-se na região Sudoeste do estado do Pará, sua sede está situada às margens da Rodovia Transamazônica, a 46 quilômetros de Altamira. Seu território abrange uma área de $6.362,575 \mathrm{~km}^{2}$, e e acordo com o IBGE, a população estimada do município é de 14.883 habitantes (IBGE, 2021a). E o município de Uruará também pertence à mesorregião Sudoeste do estado do Pará, localizado as margens da Rodovia Transamazônica, a 180 quilômetros de Altamira. Segundo o IBGE, a população de Uruará é de 45.395 habitantes em 10.791,406 km² (IBGE, 2021b).

No município de Uruará, as entrevistas foram realizadas nas localidades do $\mathrm{Km}$ 147, km 170 Norte, Travessão do Zero e Km 130. E em Brasil Novo, as entrevistas foram realizadas na localidade Vicinal 16. Foram entrevistados 10 agricultores familiares, sendo 5 produtores convencionais e 5 orgânicos. Foi considerado produtor orgânico aquele certificado como tal via auditoria contratada pelas cooperativas de produção orgânica da região.

Trata-se de uma pesquisa quanti-qualitativa, ou seja, envolve a geração e análise de dados quantitativos e qualitativos. Esse tipo de pesquisa permite um cruzamento maior de dados e o valor da pesquisa cresce juntamente com a validação das informações.

Para se obter as informações necessárias foram realizadas entrevistas semiestruturadas utilizando um guia composto por um conjunto de perguntas em campos temáticos ligados às dimensões da sustentabilidade. Após a coleta, todos os dados foram sistematizados em planilha excel, gerando gráficos para a comparação entre os sistemas por MESMIS.

\subsection{ATRIBUTOS, PARÂMETROS E CRITÉRIOS UTILIZADOS}

Para análise dos sistemas, Gliesman (2001) se utiliza do conceito de agroecossistema como um local de produção agrícola compreendido como um ecossistema estudado em seus aspectos estruturais e funcionais. Para representá-lo devese ter conhecimento dos princípios ecológicos que dinamizam os ecossistemas naturais, e assim, compreendê-los como um sistema ecológico dinâmico no qual se processam fluxos de energia e matéria (ciclagem de nutrientes) entre os seus componentes bióticos e abióticos interativos e interdependentes. 
O Marco de Avaliação de Sistemas de Manejo Incorporando Indicadores de Sustentabilidade (MESMIS) tem sido muito utilizado como ferramenta de avaliação, principalmente em unidades produtivas de base familiar e se apresenta como um ótimo exemplo para avaliação de sustentabilidade. Sua estrutura baseia-se em atributos de um agroecossistema sustentável, como a produtividade, estabilidade, adaptabilidade, equidade e auto dependência, que se classifica como a capacidade do sistema de controlar e regular suas relações com o seu exterior (SILVA, 2017; FERRAZ, 2003).

De acordo com Nogueira (2012, p.27): “o MESMIS tem como premissa a abordagem sistêmica e a construção participativa dos indicadores mediante envolvimento dos diversos agentes e atores do meio a ser estudado".

Esta ferramenta permite adaptação que se molde às realidades estudadas (SILVA, 2017). O intuito é comparar os agroecossistemas e responder a perguntas como: o que leva a determinado agroecossistema ser mais sustentável? Em que aspecto o agroecossistema deve ser melhorado visando sua sustentabilidade? Além disso, dar subsídios para elaboração de propostas de programas de desenvolvimento que atendam às necessidades de cada realidade (NOGUEIRA, 2012).

No Quadro 1 estão apresentados os atributos, parâmetros e critérios para análise da dimensão ambiental da sustentabilidade utilizados para avaliar os agroecossistemas. No Quadro 2 constam os da dimensão social, e no Quadro 3, os da dimensão econômica.

Cada parâmetro foi classificado por um escore: zero, cinco ou dez. $\mathrm{Na}$ representação gráfica, quanto mais próximo de 10, mais sustentável é naquele conjunto de parâmetros do atributo.

Quadro 1: Dimensão Ambiental.

\begin{tabular}{|l|l|l|}
\hline ATRIBUTOS & Parâmetros & Critérios \\
\hline $\begin{array}{l}\text { Manutenção da diversidade } \\
\text { natural }\end{array}$ & $\begin{array}{l}\text { Manutenção da vegetação } \\
\text { natural }\end{array}$ & Percentual de mata. \\
\cline { 2 - 3 } & SAFs implantados & $\begin{array}{l}\text { Percentual de SAFs } \\
\text { implantados }\end{array}$ \\
\hline $\begin{array}{l}\text { Diversidade de espécies } \\
\text { cultivadas }\end{array}$ & $\begin{array}{l}\text { Nível de diversidade Intra- } \\
\text { cultivo }\end{array}$ & Número de espécies cultivadas \\
\cline { 2 - 4 } & $\begin{array}{l}\text { Nível de diversidade das } \\
\text { atividades produtivas }\end{array}$ & $\begin{array}{l}\text { Número de atividades } \\
\text { produtivas }\end{array}$ \\
\hline Limitações impostas ao meio & Uso de insumos químicos & $\begin{array}{l}\text { Quantidade de insumos } \\
\text { químicos utilizados }\end{array}$ \\
\cline { 2 - 4 } & Uso de insumos orgânicos & $\begin{array}{l}\text { Quantidade e tipos de insumos } \\
\text { orgânicos utilizados }\end{array}$ \\
\cline { 2 - 4 } & Erosão visível & Nível de erosão observado \\
\cline { 2 - 4 } & Escassez hídrica & Nível de escassez hídrica \\
\hline
\end{tabular}


Quadro 2: Dimensão social

\begin{tabular}{|c|c|c|}
\hline ATRIBUTO & Parâmetros & Critérios \\
\hline \multirow[t]{5}{*}{ Qualidade de vida familiar } & Serviços de saúde & $\begin{array}{l}\text { Nível de atuação do agente de } \\
\text { saúde na comunidade }\end{array}$ \\
\hline & Serviços de saneamento básico & $\begin{array}{l}\text { Quantidade de banheiro com } \\
\text { fossa; tipos de tratamento para } \\
\text { água. }\end{array}$ \\
\hline & Serviços de educação & $\begin{array}{l}\text { Existência de escolas com nível } \\
\text { fundamental e/ou médio. }\end{array}$ \\
\hline & Situação da saúde da família & $\begin{array}{l}\text { Existência de indivíduos com } \\
\text { problemas de saúde. }\end{array}$ \\
\hline & Escolaridade da família & Nível de escolaridade da família \\
\hline \multirow[t]{3}{*}{ Nível de organização } & Participação em organizações & $\begin{array}{l}\text { Existência de associados às } \\
\text { organizações }\end{array}$ \\
\hline & $\begin{array}{lll}\begin{array}{l}\text { Participação } \\
\text { coletivas }\end{array} & \text { nas decisões } \\
\end{array}$ & $\begin{array}{l}\text { Nível de participação nas } \\
\text { decisões coletivas. }\end{array}$ \\
\hline & $\begin{array}{l}\text { Diálogo com os técnicos de } \\
\text { ATER }\end{array}$ & $\begin{array}{l}\text { Nível de acesso aos técnicos de } \\
\text { instituições públicas }\end{array}$ \\
\hline \multirow[t]{4}{*}{$\begin{array}{l}\text { Capacidade de Trabalho } \\
\text { familiar }\end{array}$} & Contratação de mão de obra & $\begin{array}{l}\text { Nível de contratação de mão de } \\
\text { obra externa }\end{array}$ \\
\hline & Trabalho fora do lote & $\begin{array}{l}\text { Frequência de trabalho externo } \\
\text { ao lote }\end{array}$ \\
\hline & Momento de descanso / Lazer & $\begin{array}{l}\text { Existência de atividades de lazer } \\
\text { e descanso. }\end{array}$ \\
\hline & $\begin{array}{l}\text { Capacidade de cobrir demanda } \\
\text { interna }\end{array}$ & $\begin{array}{l}\text { Nível de participação dos } \\
\text { membros da família para suprir } \\
\text { demanda interna }\end{array}$ \\
\hline
\end{tabular}

Quadro 3: Dimensão econômica

\begin{tabular}{|c|c|c|}
\hline ATRIBUTO & Parâmetro & Critério \\
\hline \multirow{3}{*}{$\begin{array}{l}\text { Performance da } \\
\text { economia familiar }\end{array}$} & Renda familiar per capita & Valor da renda per capita. \\
\hline & $\begin{array}{l}\text { Importância das atividades } \\
\text { produtivas }\end{array}$ & $\begin{array}{l}\text { Percentual de contribuição da renda } \\
\text { das atividades produtivas na economia } \\
\text { familiar }\end{array}$ \\
\hline & Importância da renda externa & $\begin{array}{l}\text { Percentual da renda externa na } \\
\text { economia familiar. }\end{array}$ \\
\hline $\begin{array}{l}\text { Endividamento } \\
\text { familiar }\end{array}$ & Dívidas contraídas & Número e tipos de dívidas \\
\hline \multirow[t]{4}{*}{ Eficiência do manejo } & Rendimento físico médio & $\begin{array}{l}\text { Número de bons resultados em relação } \\
\text { ao rendimento físico. }\end{array}$ \\
\hline & Perda no rendimento físico & $\begin{array}{l}\text { Número de maus resultados em relação } \\
\text { ao rendimento físico }\end{array}$ \\
\hline & $\begin{array}{l}\text { Diversidade de atividades } \\
\text { produtivas }\end{array}$ & Número de atividades produtivas. \\
\hline & $\begin{array}{l}\text { Dependência de } \\
\text { externos }\end{array}$ & $\begin{array}{l}\text { Quantidade de vezes que utiliza } \\
\text { insumos externos. }\end{array}$ \\
\hline \multirow{4}{*}{$\begin{array}{ll}\text { Possibilidades } & \text { de } \\
\text { diversificação } & \text { do } \\
\text { agroecossistema } & \end{array}$} & $\begin{array}{l}\text { Diversidade das linhas de } \\
\text { crédito disponíveis }\end{array}$ & $\begin{array}{l}\text { Quantidade de linha de crédito } \\
\text { disponível. }\end{array}$ \\
\hline & Diversificação atual & Número de atividades do sistema \\
\hline & Vontade de diversificar & $\begin{array}{l}\text { Grau de interesse pela diversificação } \\
\text { do sistema }\end{array}$ \\
\hline & $\begin{array}{lll}\begin{array}{l}\text { Manutenção } \\
\text { natural }\end{array} & \text { da } & \text { vegetação } \\
\end{array}$ & Percentual de desmatamento. \\
\hline
\end{tabular}


Os agroecossistemas de 1 a 5 são os convencionais identificados pelas letras AC, em contraponto aos que usam técnicas orgânicas identificado pelas iniciais AO, representados pelos cooperados da COPOPS (Cooperativa de Produtores Orgânicos Perpétuo Socorro) do município de Uruará e da COPOXIN (Cooperativa dos Produtos Orgânicos do Xingu) de Brasil Novo.

\section{RESULTADOS E DISCUSSÃO}

As famílias entrevistadas chegaram como migrantes a partir dos anos de 1970. Com relação ao tempo de moradia em suas propriedades atuais, varia entre 5 a 40 anos. Suas propriedades têm áreas de 6 a 100 hectares, sendo as áreas menores resultado de partilha de herança ou compra de chácaras em regiões de solos de maior fertilidade química, como as terras roxas estruturadas (nitossolo vermelho) para o plantio de cacau (Theobroma cacao). As propriedades com área de 100 hectares seguem o módulo fiscal padronizado no período da colonização oficial adotado na região, e combinam atividades de pecuária bovina e de cultivos.

Existem quatro cooperativas de produtores orgânicos em funcionamento na região (Tabela 1), que apesar do quantitativo ainda pequeno de cooperados, o sistema de comercialização via essas cooperativas se estende a outros produtores que estão em transição para sistemas orgânicos (ZAMORIN, 2017).

Tabela 1. As cooperativas de produção orgânica certificada da região

\begin{tabular}{|c|c|c|c|c|c|c|c|}
\hline \multirow[t]{2}{*}{ Cooperativa } & \multirow[t]{2}{*}{ Município } & \multirow[t]{2}{*}{$\begin{array}{ll}\mathrm{N}^{\mathrm{o}} & \mathrm{de} \\
\text { cooperados }\end{array}$} & \multicolumn{2}{|c|}{$\begin{array}{l}\text { Área total de } \\
\text { cacau (ha) }\end{array}$} & \multicolumn{2}{|c|}{$\begin{array}{l}\text { Total em Produção } \\
\text { (ton) }\end{array}$} & \multirow{2}{*}{$\begin{array}{l}\text { Área total } \\
\text { certificada } \\
\text { (ha) }\end{array}$} \\
\hline & & & $\begin{array}{l}\text { Área } \\
\text { total }\end{array}$ & $\begin{array}{l}\text { Área de } \\
\text { produção } \\
\text { de cacau } \\
\text { orgânico }\end{array}$ & $\begin{array}{l}\text { Produção } \\
\text { total de } \\
\text { cacau }\end{array}$ & $\begin{array}{l}\text { Produção } \\
\text { de cacau } \\
\text { orgânico }\end{array}$ & \\
\hline COPOXIN & Brasil Novo & 43 & 274,5 & 87,1 & 128,126 & 30,226 & 1791,75 \\
\hline COPOPS & Uruará & 31 & 293,2 & 111,7 & 141,78 & 51,38 & 1859,5 \\
\hline COPOTRAN & Medicilândia & 16 & 85,9 & 46,4 & 30,78 & 16,16 & 833,5 \\
\hline COOPCAO & Pacajá & 13 & 109,5 & 105 & 51,2 & 49,2 & 1083 \\
\hline Total & & 103 & 763,1 & 350,2 & 351,886 & 146,966 & 5567,75 \\
\hline
\end{tabular}

Fonte: pesquisa de campo/dados da COPOPS (2018)

Os produtores que realizam a produção orgânica têm no cacau o produto central da certificação, e consequentemente, da comercialização. Neste sentido, a cacauicultura 
é o a atividade primordial para se entender como ocorre a produção orgânica dessas famílias.

No Brasil, a legislação que regulamenta a agricultura orgânica é o Decreto $\mathrm{N}^{\circ}$ 6.323, de 27 de dezembro de 2007, onde trata no capítulo I, art. $2^{\circ}$ a definição do sistema orgânico de produção agropecuária como:

Todo aquele em que se adotam técnicas específicas, mediante a otimização do uso dos recursos naturais e socioeconômicos disponíveis e o respeito à integridade cultural das comunidades rurais, tendo por objetivo a sustentabilidade econômica e ecológica, a maximização dos benefícios sociais, a minimização da dependência de energia nãorenovável, empregando, sempre que possível, métodos culturais, biológicos e mecânicos, em contraposição ao uso de materiais sintéticos, a eliminação do uso de organismos geneticamente modificados e radiações ionizantes, em qualquer fase do processo de produção, processamento, armazenamento, distribuição e comercialização, e a proteção do meio ambiente (BRASIL, 2007).

A Figura 1 destaca o bom desempenho dos sistemas convencionais nos atributos ligados à dimensão econômica, mas com desempenho inferior nas demais dimensões. Com destaque para o AC 2 em seus parâmetros econômicos e nível de organização.

Figura 1. Gráfico de avalição de sustentabilidade dos agroecossistemas convencionais $(\mathrm{AC})$

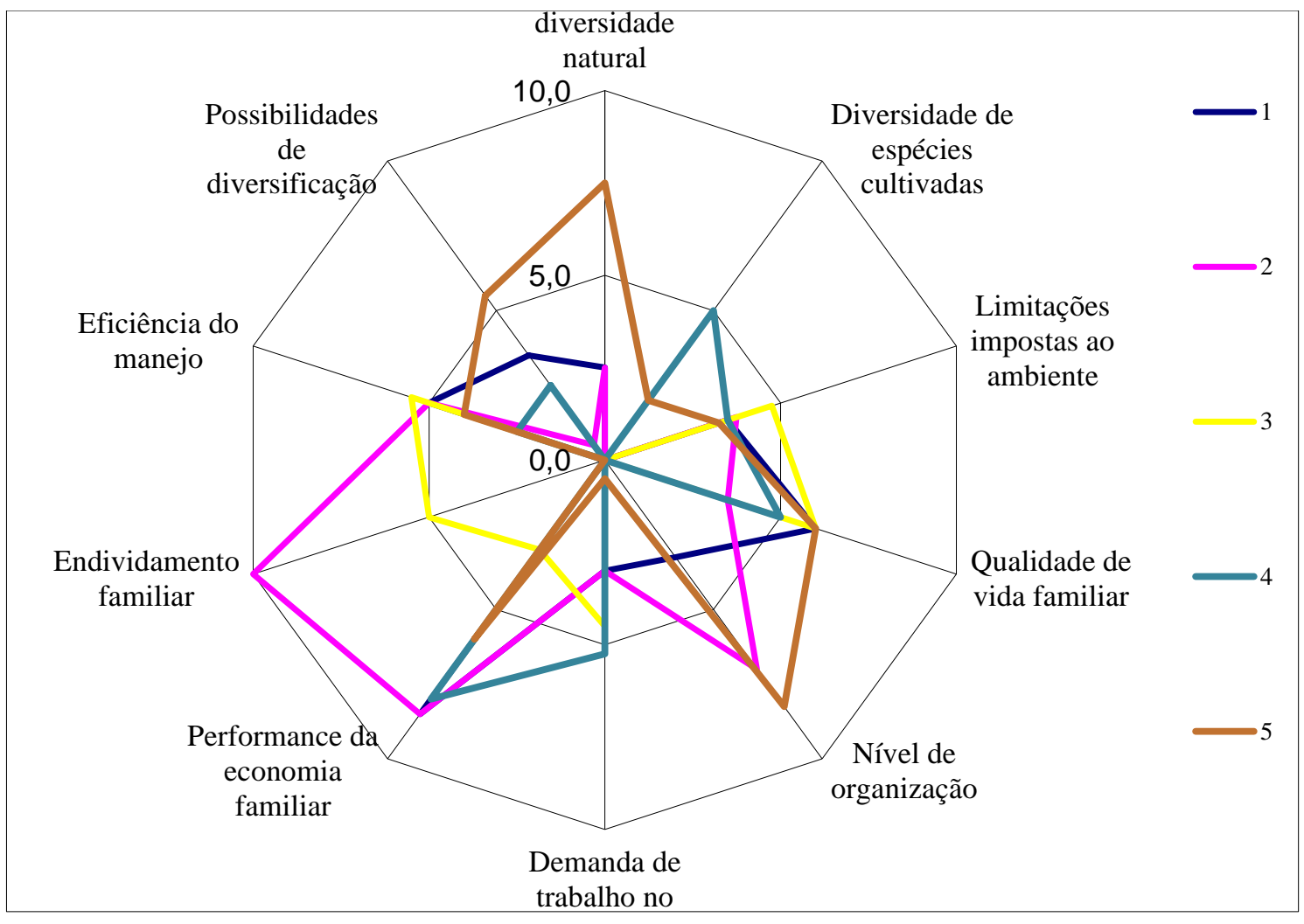

Fonte: pesquisa de campo (2018) 
Na Figura 2 pode ser observado o desempenho dos sistemas orgânicos, dando enfoque em seus pontos positivos, assim como também suas fraquezas com relação à sustentabilidade. Destaca-se o bom desempenho nos atributos ligados à dimensão ambiental e organizacional.

E a Figura 3 mostra a performance dos dez agroecossistemas, identificando graficamente o nível de sustentabilidade relativo alcançado pelos mesmos. Identificando quais se encontram em um estado crítico e quais alcançaram um melhor resultado. $\mathrm{O}$ gráfico está divido entre sistemas convencionais (1, 2, 3, 4 e 5) e orgânicos $(6,7,8,9$ e 10). Os critérios utilizados para a avaliação da sustentabilidade estão envolvidos nas três dimensões.

Figura 2. Gráfico de avalição de sustentabilidade dos agroecossistemas orgânicos

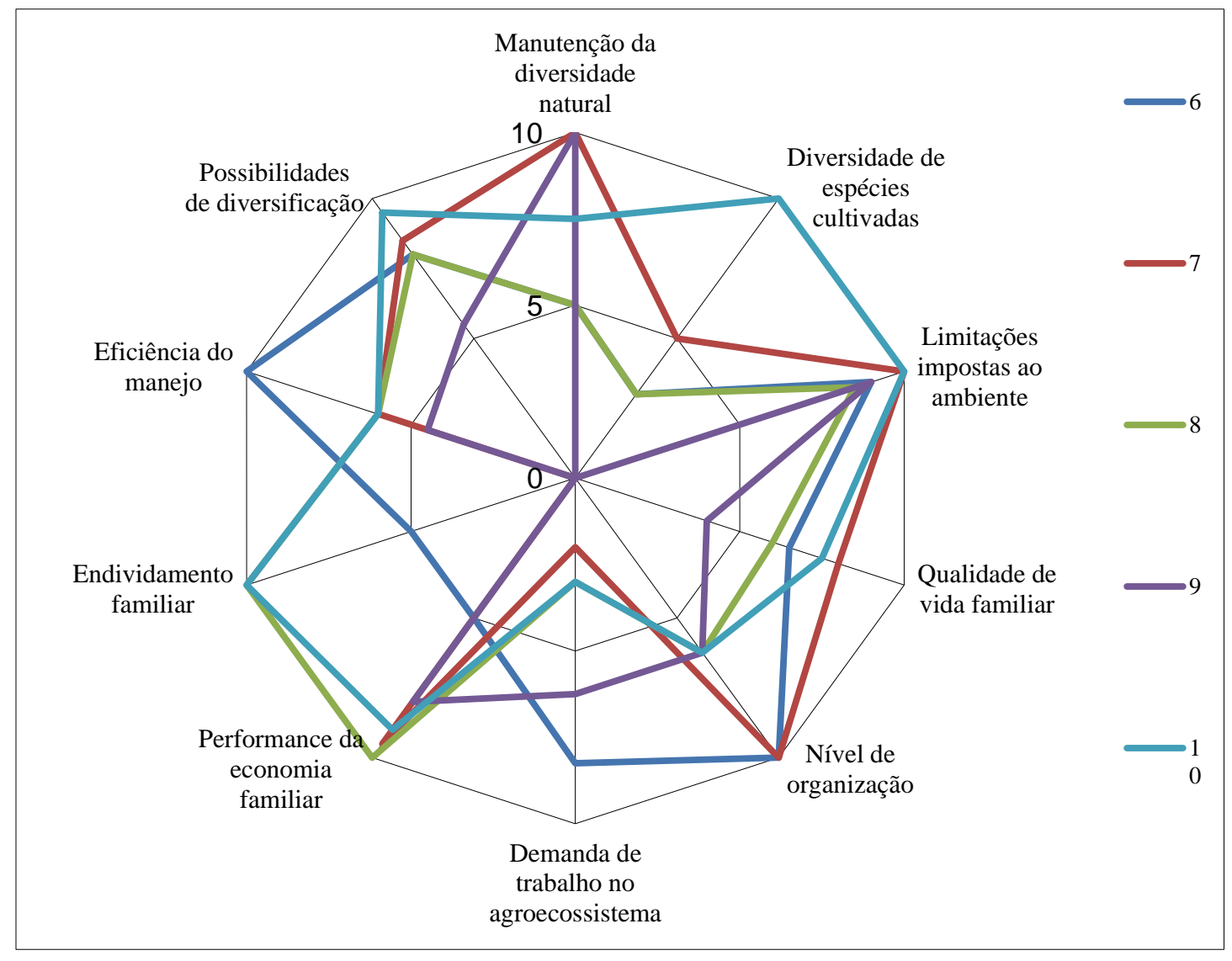

Fonte: pesquisa de campo (2018)

A Figura 3 aponta que todos os sistemas convencionais tem resultados abaixo do nível crítico, além de um orgânico (AO 9) que apresentou baixa diversidade de espécies cultivadas e o mesmo possui dívida de crédito rural. Em contraste, quatro dos orgânicos estão no nível de sustentabilidade mais elevado da amostra. 
Figura 3. Comparação entre os agroecossistemas orgânicos e convencionais nas três dimensões

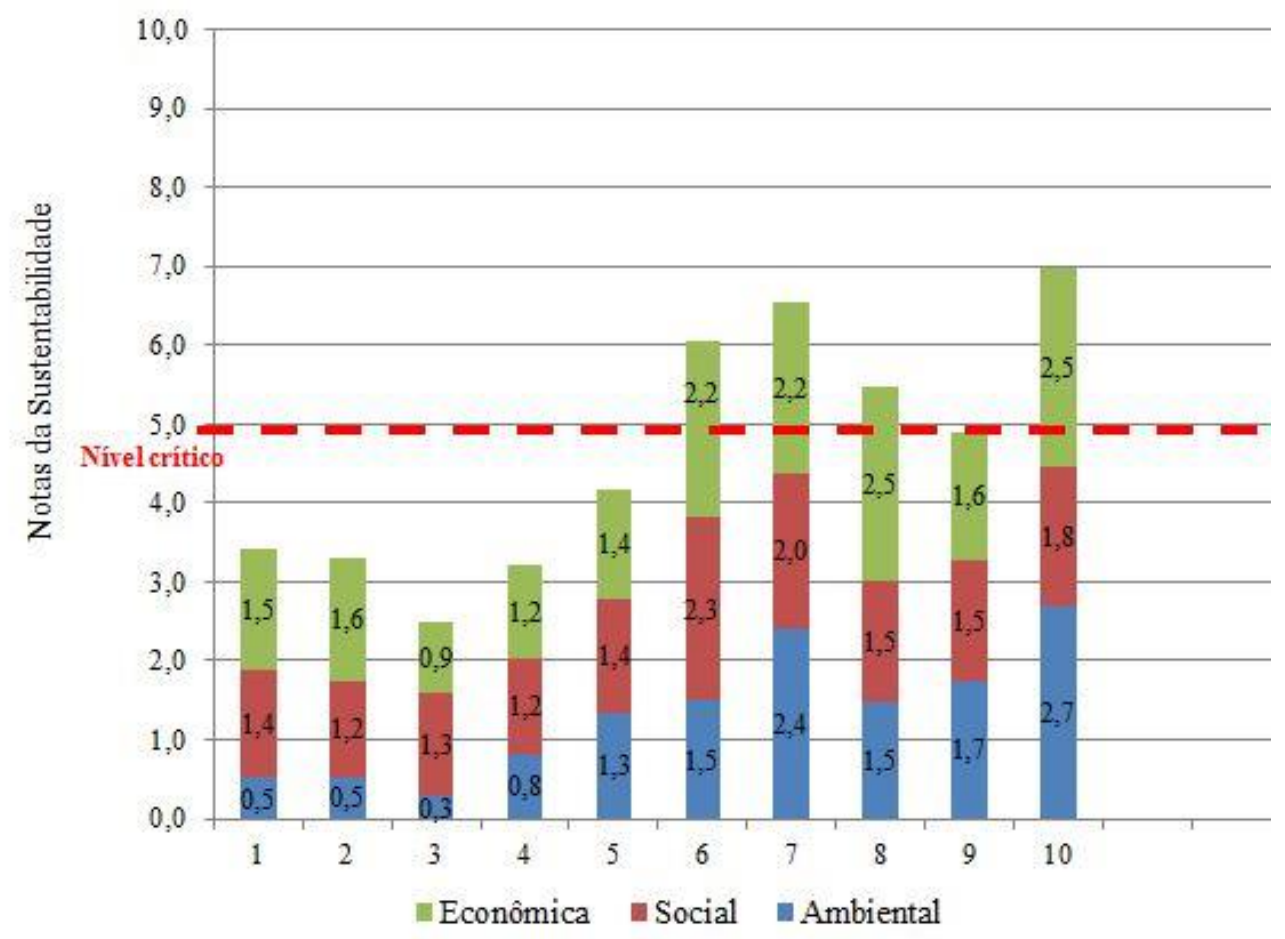

Fonte: Pesquisa de campo (2018)

Os agroecossistemas com melhores desempenhos na avaliação geral de sustentabilidade são os mesmos que estão com a produção orgânica mais consolidada, ou seja, são os que as famílias desenvolvem práticas orgânicas, principalmente incorporaram os princípios da agricultura orgânica como uma estratégia da família (SILVA, 2013).

$\mathrm{Na}$ dimensão ambiental o desempenho de todos ficou no nível mais baixo. Dos dez sistemas, oito apresentaram um nível altamente crítico (Figura 3). Isso está relacionado com a trajetória de implantação de sistemas extensivos que levou ao índice de desmatamento atual de suas áreas. Além disso, a maioria não fez a implantação de sistemas agroflorestais e não possuem diversidade de espécies intra cultivo.

Dentre os agroecossistemas que apresentaram insustentabilidade neste parâmetro, os AC 3 e AC4 se mostram mais crítico, visto que esses mantêm apenas $20 \%$ da mata nativa. Já o AC 1 e AC2 mantêm de $20 \%$ a $50 \%$ e o AC 5 mantém acima de $50 \%$ da mata nativa do lote.

Já em relação aos agroecossistemas orgânicos, identifica-se que apenas o AO 8 mantém a mata abaixo de $50 \%$ da área do lote, já os demais possuem mais de $50 \%$ e 
possuem sistemas agroflorestais, apresentando maior diversidade tanto de cultivos quanto de atividade produtivas.

A dimensão ambiental é um dos aspectos para garantir a sustentabilidade dos agroecossistemas em longo prazo (SILVA, 2008; CAPORAL; COSTABEBER, 2002). De acordo com Silva (2013) estão relacionados a esta dimensão os atributos da resiliência e estabilidade dos agroecossistemas em manter-se por um longo período produzindo satisfatoriamente. Para Gliesman (2001), a sustentabilidade será mais elevada quanto maior for a complexidade das transformações, a manutenção da biodiversidade e a capacidade de resiliência do sistema.

O nível de diversidade intracultivo nas parcelas de cultivo anual foi um dos parâmetros estudados neste atributo. Neste sentido, quatro $\mathrm{AC}$ (1, 2, 3 e 5) possuem menos de 5 espécies de diversidade intra-cultivo, somente um (AC 4) realiza o cultivo de 5 espécies. Comparados aos AO, apenas um (AO 9) se mostrou em nível crítico, ou seja, cultiva menos de 5 espécies, três (AO 6, 7 e 8) cultivam 5 espécies e um (AO 10) cultiva mais de 10 espécies em suas parcelas de cultivo anuais. Aqui não foram consideradas as plantas do quintal e hortas domésticas.

Outro parâmetro analisado neste atributo foi o nível de diversidade de atividades produtivas de cada sistema. Este parâmetro mostrou a maioria das famílias conduziu seus sistemas para a especialização, visto que dos dez, sete (AC 1, 2 e 3, AO 6, 8 e 9) reproduzem em suas propriedades somente até 2 atividades produtivas, três (AC 4 e 5 , e AO 7) têm de 3 a 4 atividades desenvolvidas e apenas uma (AO 10) tem 5 atividades realizadas no sistema de produção.

Com base nos resultados obtidos com a ferramenta percebe-se que no atributo de limitações impostas ao meio, o uso de insumos químicos é praticado prioritariamente pelos AC, visto que os AO são regidos por regras impostas pela certificadora, dentre elas, de somente usar insumos orgânicos. Dos AC, três (1, 4 e 5) relatam usar com frequência insumos químicos para produção de seus produtos, somente dois (AC 2 e 3) dizem usar esses insumos de forma esporádica em suas propriedades. No parâmetro de uso de insumos orgânicos é notável que todos os $\mathrm{AO}$ fazem uso do mesmo. E entre os AC todos dizem não usar.

Identifica-se que na questão ambiental os sistemas orgânicos se mostraram ser mais sustentáveis do que os sistemas convencionais. Isto se deve ao fato de que para certificação orgânica são adotadas inúmeras regras, atrelado a isso, o próprio produtor 
orgânico, a partir do momento que passa a ter conhecimento a respeito de formas alternativas de lidar com a terra, consegue colocar algumas em prática.

Entretanto, foram apontadas pelos produtores diversas dificuldades para manejo dos sistemas orgânicos, de ordem técnica, de infraestrutura e social: demora no pagamento das vendas realizadas via cooperativa; realização das etapas de fermentação e secagem conforme as regras de qualidade; restrição quanto ao uso do corte e queima; falta de motivação, participação e diálogo na cooperativa e entre os cooperados; falta de conhecimento sobre quais as técnicas que devem utilizar, como os tipos de adubos; realizar o controle de pragas e de plantas espontâneas sem uso de agroquímicos; falta de mão de obra e de infraestrutura/benfeitorias.

Na dimensão social considera-se a participação da família no cenário social em que se insere, busca-se verificar como as pessoas acessam os seus direitos primordiais para garantir sua cidadania. No que remete a sustentabilidade social o acesso aos serviços básicos de saúde, de ensino escolar, saneamento básico, são essenciais para a manutenção de uma relação digna dos envolvidos.

Os atributos verificados nesta dimensão foram: qualidade de vida familiar, nível de organização e capacidade de trabalho familiar.

No atributo qualidade de vida da família em termos do serviços de saúde, o critério utilizado para este tipo de serviço foi avaliar o nível de atuação do agente de saúde na comunidade, neste sentido nota-se com base nos resultados que todos os entrevistados dos $\mathrm{AO}$, se mostram insatisfeitos, declarando que esses agentes são pouco atuantes no local onde moram. Já os entrevistados dos AC, quatro (1, 2, 3 e 4) relatam que este serviço é bom, e um (AC 5) diz não terem esse serviço para sua família. Para Freitas, Giatti e Sobral (2010) na concepção de sustentabilidade, a saúde não pode ser tratada como dissociada do bem-estar e das mudanças socioambientais e seus impactos nos ecossistemas. Por exemplo, os relatos de intoxicação humana são mencionados como motivo que levou alguns a evitar o uso de agrotóxicos.

Os resultados obtidos no parâmetro de serviços de saneamento básico demonstram que de todos os envolvidos nas entrevistas, somente um (AC 3) se mostra insatisfeito com o serviço. Neste parâmetro foi avaliada a questão de essas famílias terem banheiro com fossa em suas residências, bem como algum tipo de tratamento da água.

Quanto à educação, um critério para avaliação foi a questão de existência de escolas com nível fundamental e/ou médio nos locais onde as famílias vivem. Com base 
nos resultados, verifica-se que se tem acesso às escolas na comunidade ou próximo a mesma para o ensino fundamental, mas o ensino médio é ofertado na sede do município ou vilas.

A respeito da escolaridade das famílias, constatou que duas AO (7 e 8) têm pelo menos um membro com ensino superior, duas AO (6 e 10) com algum membro com ensino médio e uma (AO 9) com ensino fundamental incompleto. Com relação aos AC, verifica-se que uma (AC 1) com ensino superior, uma (AC 2) com ensino médio e três (3, 4 e 5) possuem membros com ensino fundamental incompleto.

Em relação ao nível de organização, a participação em organizações foi identificada com a análise do critério de existência de associados na família. Nos agroecossistemas orgânicos, dois (AO 6 e 7) estão participando ativamente da cooperativa. As reuniões nas cooperativas ocorrem de forma frequente, para tomada de decisões com objetivos em comum, abordando questões ligadas à comercialização, ajustes administrativos, programação, etc.

De acordo com os resultados, a atuação da assistência técnica é mais frequente em sistemas de produção orgânica, $100 \%$ dos entrevistados dizem ter este tipo de atendimento, tanto pelos técnicos da cooperativa, quanto de entidades parceiras vinculadas ao programa. Já os AC, somente um (5) tem acesso ao acompanhamento técnico, dois (AC 1 e 2) assumem ter somente esporadicamente e dois (AC 3 e 4) relatam não terem tido acesso.

A dimensão econômica da sustentabilidade está relacionada com os atributos de produtividade, capacidade do agroecossistema de gerar ganhos e rendimento com a estabilidade, e sua manutenção no tempo (MASERA et al., 1999; SILVA, 2008).

No desempenho econômico foram avaliados quatro atributos, com o objetivo de analisar a sustentabilidade nesta dimensão. $O$ atributo de performance da economia familiar, endividamento familiar, eficiência de manejo e possibilidades de diversificação do agroecossistema. No entanto, diante dos resultados, dois atributos se mostraram mais relevantes: performance econômica e endividamento.

Pelos valores declarados pelos entrevistados de renda familiar per capita, identificou-se que apenas o AC 3 apresentou renda per capita de até meio salário mínimo. Três (AC 5, AO 6 e AO 9) contam com valores de 0,5 a 0,75 do salário mínimo per capita. E as outras seis famílias declararam valores acima de 0,75 salário mínimo per capita por mês. 
A importância das atividades agropecuárias para composição da renda familiar se mostrou como um parâmetro de extrema importância, principalmente para os AOs, visto que todos estes sistemas apresentaram que os valores que ganham com estas atividades contribuem com mais de $80 \%$ da renda total. Entre os AC verifica-se que três (AC 1, 2 e 3) que $50 \%$ a $70 \%$ da renda advém das atividades agropecuárias, e para os AC 4 e AC5, representam $89 \%$ da renda.

$\mathrm{O}$ atributo endividamento familiar mostrou como forte limitante para $\mathrm{o}$ desempenho da economia dessas famílias. Os AC 1, 4 e 5 têm dívidas com crédito agrícola bancário, o AC 3 relata ter dívidas de forma esporádica e apenas o AC 2 diz não ter dívida de forma alguma. Com relação aos AO, percebe-se que dois (7 e 9) possuem dívidas contraídas por crédito bancário e apenas os AO 8 e 10 não tem nenhuma dívida.

Os desafios encontrados para o desenvolvimento de agroecossistemas sustentáveis na região é conciliar os objetivos econômicos em curto prazo e as condições ambientais. No entanto, desenvolver e assegurar agroecossistemas sustentáveis é diminuir o avanço sobre as áreas de florestas, dar condições de permanência das populações do campo e melhorar a qualidade de vida para as mesmas.

Outro desafio identificado é que as famílias que buscam apoio na agroecologia e neste caso, na produção orgânica, se ressentem da falta de suporte institucional e organizacional em termos de políticas específicas, conforme estava sendo construído no Plano Nacional de Agroecologia e Agricultura Orgânica, tornando-se sem efeito a partir dos governos Temer e Bolsonaro. Nesse plano eram estabelecidas ações articuladas em termos de assistência técnica, crédito, infraestrutura, comercialização e mercados, organização social, dentre outras, que permitiam fortalecer as iniciativas de produção sustentável visando fornecer alimentação saudável à população. Dessa forma, não se pode produzir sem pensar em inserir os produtos em mercados justos, bem como, em garantir políticas sociais para melhoria na qualidade de vida das famílias, como acesso à educação diferenciada, serviços de saúde, energia elétrica, estradas, comunicação e cultura.

\section{CONSIDERAÇÕES FINAIS}

Em relação ao desempenho ambiental, as famílias dos agroecossistemas convencionais tem sistemas com menor diversificação de espécies, bem como possui percentual maior de áreas desmatadas. 
Os agroecossistemas orgânicos alicerçados nas exigências da certificação e consequentemente na vontade de produzir produtos de melhor qualidade, apresentaram melhores desempenhos na avaliação de sustentabilidade econômica, social e principalmente na ambiental. No entanto, mesmo apresentando resultados satisfatórios comparados aos convencionais, se faz necessário que em alguns atributos sejam melhorados, inclusive nas práticas produtivas.

Os sistemas orgânicos se destacaram em termos de sustentabilidade em quase todos os parâmetros, e em termos econômicos, a inserção em mercados orgânicos certificados gera melhor rendimento financeiro, assim como por estarem com menor grau de endividamento e maior inserção organizativa. Por outro lado, esses sistemas precisam ampliar sua performance nos mercados locais e regionais oferecendo subprodutos artesanais ou industrializados.

Dentre os parâmetros apresentados em cada dimensão, conclui-se que os indicadores da dimensão ambiental foram os que tiveram menor destaque em termos de sustentabilidade, ou seja, mesmo as famílias que se dedicam à produção orgânica tem maior dificuldade de manter as práticas de manejo orgânico, enunciados principalmente pelos parâmetros da manutenção da agrobiodiversidade. Outro elemento evidenciado que tem influenciado na diminuição da sustentabilidade ambiental dos sistemas é a eficiência do manejo, ou seja, mesmo nos sistemas de produção orgânica, verifica-se a necessidade de interferir para melhorar a fertilidade e biodiversidade do meio, e assim, contribuir para estabelecer uma dinâmica ecológica mais equilibrada do sistema.

\section{REFERÊNCIAS}

ALTIERI, M. Agroecologia: as bases científicas da agricultura alternativa. Rio de Janeiro: PTA/FASE, 1989.

ALTIERI, M.; NICHOLLS, C. I. Agroecologia: teoría y práctica para una agricultura sustentable. México: PNUMA y Red de formación ambiental para América Latina y el Caribe, 2000. 250p.

BELLON, S. The relationships between organic farming and agroecology. ISOFAR -International Society of Organic Agriculture Research, 2011.

BRASIL. Lei N 10831, DE 23 DE DEZEMBRO DE 2003. Dispõe sobre a agricultura orgânica e dá outras providências. Publicado no Diário Oficial da União de 24/12/2003, Seção 1, Página 8. 
BRASIL. Regulamenta a Lei no 10.831, de 23 de dezembro de 2003, que dispõe sobre a agricultura orgânica, e dá outras providências. Decreto $\mathrm{N}^{\mathbf{0}} \mathbf{6 . 3 2 3}$, de 27 de dezembro de 2007.

CAPORAL, F. R.; COSTABEBER, J. A. Análise Multidimensional da Sustentabilidade: Uma proposta metodológica a partir da Agroecologia. Agroecol. E Desenv. Rur. Sustent., Porto Alegre, v.3, n.3, Jul/Set 2002.

FREITAS, C. M; GIATTI, L. L; SOBRAL, A. Sustentabilidade ambiental e de saúde na Amazônia Legal, Brasil: uma análise através de indicadores. Brasília: Organização Pan-Americana da Saúde, 2010.

FERRAZ, J. M. G. As dimensões da sustentabilidade e seus indicadores. In: MARQUES, J. F.; SKORUPA, L. A.; FERRAZ, J. M.G. Indicadores de Sustentabilidade em Agroecossistemas. Jaguariúna/SP: Embrapa Meio Ambiente, 2003, pp. 17-35

GLIESMAN, S. Agroecologia: processos ecológicos em Agricultura Sustentável. Porto Alegre: editora UFRGS, 2001.

IBGE. Cidades: município de Brasil Novo. 2021a. Disponível em: https://www.ibge.gov.br/cidades-e-estados/pa/brasil-novo.html. Acesso: 19 de janeiro de 2021.

IBGE. Cidades: município de Uruará. 2021b. Disponível em: https://www.ibge.gov.br/cidades-e-estados/pa/uruara.html. Acesso: 19 de janeiro de 2021.

IMAZON. Desmatamento na Amazônia cresce 29\% em 2021 e é o maior dos últimos dez anos. Disponível em: https://imazon.org.br/imprensa/desmatamento-naamazonia-cresce-29-em-2021-e-e-o-maior-dos-ultimos-10-anos/. Acesso em $21 / 01 / 2022$.

MARTINS, J. de S. O Poder do Atraso. Ensaios da Sociologia da História lenta. São Paulo: Hucitec, 1994.

MASERA, O; ASTIER, M; LÓPEZ-RIDAURA, S. Sustentabilidad y manejo de recursos Naturales: el marco de evaluación MESMIS. México: Mundi-Prensa, 1999. 109 p.

NIEDERLE, P. A.; ALMEIDA, L. de; VEZANNI, F. M.(orgs). Agroecologia: práticas, mercados e políticas para uma nova agricultura. Curitiba: Kairós, 2013. Disponível em: http://aspta.org.br/wp-content/uploads/2013/07/AGROECOLOGIA-praticas-mercadose-politicas.pdf

NOGUEIRA, A. C. N. Diversificação produtiva em agroecossistema familiares nos municípios de Santa Maria das Barreiras e Conceição do Araguaia, Pará.

Dissertação (mestrado) - Universidade Federal do Pará, Núcleo de Ciências Agrárias e Desenvolvimento Rural, Programa de Pós-Graduação em Agriculturas Amazônicas, Belém, 2012. 
PETERSEN, P. Agroecologia e a superação do paradigma da modernização. In:

NIEDERLE, P. A.; ALMEIDA, L.; VEZZANI, F. M. Agroecologia: práticas, mercados e políticas para uma nova agricultura. Curitiba: Kairós, 2013. p. 69-104.

ROCHA, C. G. S.; ALMEIDA, J. P. de. Lógicas de reprodução social, trajetórias produtivas e gestão do meio natural entre agricultores familiares no sudoeste do Pará, Brasil. Novos Cadernos NAEA, [S.1.], v. 16, n. 1, set. 2013. ISSN 2179-7536. Disponível em: <https://periodicos.ufpa.br/index.php/ncn/article/view/988>. Acesso em: 19 jan. 2022. doi:http://dx.doi.org/10.5801/ncn.v16i1.988.

SILVA, L. M. S. Impactos do crédito produtivo nas noções locais de sustentabilidade em agroecossistemas familiares no território sudeste do Pará. 2008, 203 f. Tese (Doutorado em Produção vegetal) Faculdade de Agronomia Eliseu Maciel, Universidade Federal de Pelotas, 2008.

SILVA, L. M. S. et al. Espaço amazônico e estado de sustentabilidade de lógicas familiares de produção: adaptações e uso do MESMIS no caso do estado do Pará. Agricultura Familiar: Pesquisa, Formação e Desenvolvimento, [S.1.], v. 11, n. 1, p. 57-70, jul. 2017. ISSN 2675-7710. Disponível em: $<$ https://periodicos.ufpa.br/index.php/agriculturafamiliar/article/view/4677>. Acesso em: 19 jan. 2022. doi:http://dx.doi.org/10.18542/raf.v11i1.4677.

SILVA, Maristela Marques; OLIVEIRA, Francisco Assis; SANTANA, Antônio Cordeiro. Mudanças socioambientais no uso da terra em Altamira, Amazônia Oriental. Novos Cadernos NAEA, [S.1.], v. 20, n. 3, maio 2018. ISSN 2179-7536. Disponível em: <https://periodicos.ufpa.br/index.php/ncn/article/view/4270>. Acesso em: 19 jan. 2022. doi:http://dx.doi.org/10.5801/ncn.v20i3.4270.

ZAMORIN, B.G.A.C. Amêndoa de cacau de alta qualidade na Transamazônica: as práticas dos agricultores familiares em função das exigências do mercado. Dissertação (Mestrado em Agriculturas Amazônicas). Universidade Federal do Pará, Belém, 2017. 